\title{
LEGITIMAÇÃO DEMOCRÁTICA, DESOBEDIÊNCIA INSTITUCIONAL E NACIONALISMOS
}

\section{DEMOCRATIC LEGITIMATION, DISOBEDIENCE INSTITUTIONAL AND NATIONALISM}

\section{Ernani de Paula Contipelli ${ }^{1}$}

Resumo: O presente artigo tem por finalidade apresentar a figura da desobediência institucional com base na teoria da legitimação democrática do direito, que se funda na atualização das disposições normativas constitucionais a partir de procedimentos de interpretação abertos aos interessados no conteúdo das decisões política, para, assim preservar o sistema de tutela da sociedade com legitimidade democrática, confiança institucional e eficácia social, com a correspondência entre os valores informantes da base axiológica constitucional com o sentimento publico de justiça. Para constatação da aplicação prática de tal teoria se adentra no sistema autonômico espanhol, o qual é apresentado em suas diretrizes essenciais, sobretudo, no que diz respeito aos hechos diferenciales, onde se inseri a temática do nacionalismo catalão, que, no momento político atual, apresenta uma série de casos de desobediência institucional realizadas pelas autoridades regionais em relação ao Poder Central espanhol e que dizem respeito às questões que caracterizam a identidade cultural dessa minoria nacional. Nesse ponto, discutese com base na teoria da legitimação democrática do direito a validade dessas manifestações e a necessidade de acomodação de suas propostas de autogoverno e autodeterminação ao sentimento de justiça que paira na consciência comum do povo catalão.

Palavras-chaves: Legitimação Democrática. Modelo Autonômico Espanhol. Desobediência Institucional.

Abstract: This article aims to present the figure of the institutional disobedience based on the theory of democratic legitimation of law, which is founded on the update of the regulatory provisions from constitutional procedures of interpretation open to those interested in the content of policy decisions, for, thus preserve the system of protection of society with democratic legitimacy, institutional trust and social effectiveness, with the correspondence between the values of the axiological constitutional basis with the feeling of public justice. For the practical application of such theory enters the Spanish autonomic organization, which is presented in its essential guidelines, especially with regard to hechos diferenciales where to insert the subject of Catalan nationalism, which, in the current political moment, presents a series of cases of disobedience institutional conducted by the regional authorities in relation to the Spanish Central Power and relate to the issues that characterize the cultural identity of this national minority. At this point, it is discussed based on the theory of democratic legitimation of law the validity of these manifestations and the need for accommodation of their proposals for self-government and selfdetermination to the sense of justice that hangs in the common consciousness of the Catalan people.

Keywords: Democratic Legitimation. Spanish Autonomic Model. Institutional Disobedience.

1 Doutor em Direito pela Pontifícia Universidade Católica de São Paulo. Professor da Universidade Comunitária da Região de Chapecó, Santa Catarina, Brasil. 


\section{Introdução}

A introdução de novas propostas teóricas de investigação do fenômeno jurídico sempre vem acompanhada por situações políticas que se desdobram na historia das civilizações e que carecem de observação cientifica não apenas para justificação de atos públicos concretos, mas, principalmente, para compartir com o Direito Positivo as reais exigências que se alternam nos quadrantes da vida social, justamente, onde a teoria da legitimação democrática do direito tende a atualizar-se, com a participação ativa dos interessados no processo de formação e desenvolvimento das decisões políticas.

Assim, para analise da desobediência institucional pretende-se partir de um breve detalhamento da teoria da legitimação democrática do direito e suas propostas, para, então, constatar sua aplicação no sistema autonômico espanhol, o qual é relatado em seus pontos essenciais, sobretudo, o tema dos hechos diferenciales, onde se inseri o nacionalismo catalão, o qual, no momento político atual, vem se desdobrando em uma serie de atos públicos concretos, dentre os quais se verifica a realização por parte das autoridades regionais de protestos por desobediências institucionais, para proteger sua identidade cultural, que a caracteriza como minoria nacional em relação ao Poder Central.

\section{Teoria da Legitimação Democrática do Direito.}

A princípio, há que se destacar que o ideal contido na base axiológica do Texto Constitucional, que retratam os objetivos expressados pelo projeto de bem comum destinado a conduzir o caminhar da sociedade ${ }^{1}$, não pode ser confundido com possíveis concretizações manifestadas por obra dos Poderes Constituídos em seu âmbito de decisões políticas, as quais corrompidas em determinadas ocasiões por interesses de caráter pragmático, nem sempre se encontram ajustadas aos critérios de justiça firmados

\footnotetext{
${ }^{1}$ Dentro das propostas teóricas apresentadas por esse artigo, a felicidade social constitui o fim do Estado e do fenômeno jurídico, representando o objetivo de seu projeto constitucional de bem comum, que, entre, outros compromissos com a sociedade deve proporcionar-lhe condições para aquisição de um conjunto de bens materiais e morais que possibilite a fruição de vida satisfatoriamente digna, com a livre e igual manifestação das potencialidades dos cidadãos, para, como, ato reflexo, favorecer um ambiente direcionado ao desenvolvimento socioeconômico de toda sociedade.
} 
pelas disposições valorativas constitucionais em correspondência com as manifestações concretas desse sentimento, que são experimentadas cotidianamente pelos cidadãos ${ }^{2}$.

Desse modo, a base axiológica constitucional, que deve ser considerada não como uma mera petição de princípios, mas sim em sua função de atribuir direitos e deveres oponíveis a todos os participantes do pacto associativo territorial, para alcançar a melhor solução na satisfação de seus interesses e deve ser objeto de proteção institucional, ou mesmo símbolo de expressão da força de movimentos sociais, quando ameaçada por possíveis ações indevidas dos próprios Poderes Constituídos.

Com efeito, dentro do contexto social podem ser encontrados diversos interesses que são manifestados pelos cidadãos e pelos mais variados grupos sociais. Esses interesses devem ser considerados jurídica e politicamente pelas autoridades incumbidas de manifestar o poder estatal em sintonia com o Texto Constitucional e a base axiológica de seu projeto de bem comum. Para dimensionar o sentido que deve ser atribuído a essa base axiológica, a função interpretativa desempenhada pelos Poderes Constituídos recebe um papel fundamental, imprimindo-lhe as feições do ideal de justiça correspondente com a realidade vivenciada socialmente no processo de formação e atualização da melhor decisão para atendimento das demandas sociais, o que exige, por uma questão de racionalidade, a participação dos agentes concernidos.

Assim, devem ser estabelecidos procedimentos lógico-racionais que, primeiro, pressupõe a delimitação do conjunto de afetados por uma decisão política, e, segundo, a participação ativa desses sujeitos em suas etapas de formação e desenvolvimento, para afastar influencias negativas de partes desinteressadas, ou mesmo a incoerência daqueles que desconhecem ou não vivenciam a questão, propiciando ao aparato tutelar estatal uma aproximação à ideia de "bem comum" esperada pela sociedade, o que possibilita a legitimação democrática de seu poder.

\footnotetext{
${ }^{2}$ Tal percepção do fenômeno jurídico é largamente admitida pelas teorias, sendo relevante destacar o pensamento de John Locke que justifica de forma lógica e necessária o direito de resistência diante de um "mau governo", compreendido como aquele que atua contrariamente aos fundamentos que possibilitaram sua legitimação, o que pode resultar, inclusive, na destituição dos maus governantes: "si aquellos que están em posesión de la autoridad pierden esse poder por causa de sus abusos, entonces el poder revierte a la sociedad, y el pueblo tiene el derecho de actuar com autoridad suprema, y de asumir la legislatura; o si ló estima beneficios, puede erigir uma nueva forma de gobierno, o depositar la vieja em otras manos" (LOCKE, John. Segundo Tratado sobre el Gobierno Civil, p. 232. Madrid: Alianza Editorial, 2012). De acordo com o pensamento de John Locke, a legitimidade do governo civil baseia-se no consenso expresso dos governados, que fundam o pacto social com a transferência parcial dos direitos naturais, guardando para si o direito de resistência a um governo ilegítimo, vale dizer, que cometa atos que violem os direitos à vida, liberdade e propriedade.
} 
Ser legitimo é ser fruto do consenso, da aceitação pelas partes envolvidas no contexto das decisões de poder. No campo político, a legitimidade deve balancear, então, os pressupostos abstratos de representatividade que possibilitam o funcionamento automático de uma parcela do sistema de poder, com elementos concretos, que denotam as exigências da realidade social. Tem-se, então, uma legitimidade jurídica, que paira sobre o conteúdo das disposições normativas positivas e que, para realizar sua dinâmica de tutela da sociedade, depende de uma legitimidade democrática, obtendo a confiança dos cidadãos em relação às instituiçõoes de poder e condições apropriadas de eficácia social na condução da sociedade. Com a maior correspondência entre legitimidade jurídica e democrática, a partir da adoção dos adequados procedimentos interpretativos podem ser incrementados os atributos de confiança e eficácia social, para interpretar a base axiológica constitucional, de maneira tal a sedimentar, solidamente, suas repostas nas pretensões ditadas pelo sentimento público de justiça.

Nesse contexto, a confiança demonstra o grau de segurança e previsibilidade em que os atores sociais podem prognosticar suas ações. Se há um alto grau de confiança dos cidadãos em relação às instituições de poder, o sistema de tutela da sociedade (jurídico e político, que representa organismos e autoridades responsáveis pela manifestação de poder estatal) revela-se estável, por proporcionar uma ampla margem de previsibilidade no que se refere às políticas públicas, permitindo o planejamento no desenrolar das relações intersubjetivas com certa segurança. Na hipótese contrária, em que as instituições de poder padecem de um baixo índice de confiança, os cidadãos não manifestam credibilidade nas decisões tomadas pelo sistema de tutela da sociedade, fazendo com que tais atos ocasionem graves consequências no campo concreto, que atingem a legitimidade democrática e, por consequência, a jurídica, colocando em risco toda estruturação construída para funcionamento da entidade estatal.

Compreende-se, então, a necessidade da geração de multiplicadores de confiança para possibilitar o adequado funcionamento do sistema de tutela da sociedade, de tal sorte que cada decisão governamental que se baseia no sentimento público de justiça, para interpretar a base axiológica constitucional em bases procedimentais, tem como resultado as correspondências comportamentais dos cidadãos e grupos sociais. Posteriormente, esses comportamentos se acomodam no sistema de tutela da sociedade, gerando, com segurança e previsibilidade, o aumento de seu grau de confiabilidade dos cidadãos em relação às instituições de poder, haja vista que as decisões governamentais 
passam a ser baseadas nos reais interesses dos agentes por ela afetados. Aqui já se pode notar a intima vinculação entre a legitimidade democrática, que promove a participação dos interessados no processo de decisão política, e a confiabilidade, que agrega a crença de que haverá correspondência entre o sistema de tutela da sociedade e suas verdadeiras demandas, o que acaba por desembocar na eficácia social.

Considerada em tais condições, a Constituição deve ser concebida em seu aspecto procedimental, encontrando-se apta para absorver e alcançar a multiplicidade de interesses existentes no plano da experiência social, dispondo sobre as regras apropriadas ao desenvolvimento dos processos de negociação e decisão jus-política, independentemente de quaisquer escolhas por formulas preconcebidas ou mesmo direcionamentos ideológicos predeterminados, o que torna possível um enfrentamento democrático entre distintas posições com a finalidade de abarcar todas as opiniões possíveis, direcionando-as ao alcance do consenso sobre a melhor forma de superação de problemas ${ }^{3}$.

Esclareça-se, desde logo, que a observação da Constituição em seu aspecto procedimental pretende alcançar com maior propriedade o plano da realidade concreta, obtendo o conteúdo da devida eficácia social em conjunto com os valores presentes em seu complexo normativo para afastar eventuais déficits democráticos de legitimidade ou desconfiança institucional. Desse modo, a visão procedimental da Constituição, firmada em um ambiente de caráter democrático, torna-a uma obra aberta, projetada para o futuro e dotada de elasticidade suficiente para consagrar valores e cumprir com os objetivos contidos no projeto constitucional de bem comum, ao buscar o sentido real de seu texto no processo de negociação jus-política entre seus agentes conformadores, diretamente interessados no regramento de determinadas temáticas.

\footnotetext{
${ }^{3}$ Sobre a ampliação do processo de debate e interpretação constitucional, com a atribuição de liberdade e abertura aos diversos interessados no ambiente social, para demonstrar sua força ativa na formação de decisões políticas ajustadas a condicionantes fático-axiológicas, Peter Häberle afirma que: "Uma teoria constitucional que se concebe como ciência da experiência deve estar em condições de, decisivamente, explicitar os grupos concretos de pessoas e os fatores que formam o espaço público (Öffentlichkeit), o tipo de realidade de que se cuida, a forma como ela atua no tempo, as possibilidades e necessidades existentes" (HÄBERLE, Peter. Hermenêutica Constitucional - A Sociedade Aberta dos Intérpretes da Constituição: Contribuição para Interpretação Pluralista e "Procedimental" da Constituição, p. 19. Porto Alegre: Sérgio Antonio Fabris, 2002). Não se pode, portanto, estabelecer um numerus clausus do rol de interpretes da Constituição, todos os afetados por determinada disposição constitucional devem participar ativamente deste processo hermenêutico que se revela como instrumento democrático para definição do verdadeiro sentido do Texto Supremo.
} 
Abre-se um parêntese para salientar que a ideia de eficácia social que se pretende expor vai além da mera produção de efeitos concretos das normas jurídicas, tendo como resultado o direcionamento dos comportamentos de todos os participantes da vida social com multiplicadores de confiança, devendo abarcar o conteúdo dessas ações em sintonia com as convicções éticas do sentimento de justiça dos cidadãos. È dizer, a partir do momento em que se concebe a Constituição em uma acepção aberta, procedimental e, principalmente, democrática, suas disposições, nada mais faz, do que declarar a verdadeira necessidade dos cidadãos interessados em suas temáticas, de tal modo que a devolução, a reação concreta desse círculo virtuoso se compatibiliza com as exigências já manifestadas, o que implica em um encadeamento lógico de maior aderência a suas diretrizes para maximização de efeitos sociais concretos.

Conclui-se, com tais afirmações, que o processo de construção interpretativa da base axiológica constitucional deve ser assentado nos atributos da legitimidade democrática, confiança e eficácia social, os quais, em relação complementar, proporcionam a melhor solução no atendimento das demandas dos cidadãos e fazer valer o sentimento publico de justiça, especialmente, no que se refere às questões relativas sobre descentralização política.

\section{Sistema Autonômico Espanhol e Hechos Diferenciales.}

A Constituição Espanhola de 1978 resultou de um amplo processo de democratização que se instaurou no país após a morte do ditador Francisco Franco, onde se buscava o rompimento como o antigo modelo de exercício centralizado de poder, com a restauração das identidades regionais suprimidas durante a ditadura, bem como a atribuição de maior liberdade nas decisões locais e participação nas nacionais, o que conduziu a institucionalização de uma proposta destinada a conferir alto grau de descentralização política e administrativa das unidades constitutivas do sistema organizacional, com a formação das Comunidades Autônomas.

No entanto, em razão das disputas havidas entre as múltiplas tendências políticas existentes no período de elaboração do Texto Constitucional, principalmente, envolvendo os autonomistas e centralistas, as disposições relativas à própria formação e distribuição de poder para as Comunidades Autônomas restaram demasiadamente

abertas, fazendo com que o Poder Constituinte optasse na questão referente à organização do Estado Autonômico por sua construção paulatina, ao longo do tempo, 
com a força da ação de poderes constituídos (sobretudo, legislativo e judiciário), o que não permitiu, numa etapa inicial, rotular este modelo como uma espécie peculiar de Estado Federal ou qualquer outra modalidade conhecida.

Por certo, o Estado Autonômico, ao ser introduzido no contexto histórico-cultural em que foi concebido, revela peculiaridades que, se em determinados momentos o aproximam do federalismo, evidenciando um alto grau de descentralização do poder, também permite a revelação de traços próprios dos Estados Unitários, em especial, pelo excessivo grau de participação do poder central na definição dos assuntos de interesse das Comunidades Autônomas, o que permite dizer que este tipo estatal pode classificado como uma modalidade a parte de Estado Composto, um tipo sui generis, que se caracteriza por uma Constituição aberta, dotada de conceitos genéricos que lhe atribuem flexibilidade suficiente para construir a estrutura da organização territorial do poder mediante um amplo processo de negociação jurídica e política que encontra como centro de planejamento estratégico de suas decisões políticas a entidade central.

A respeito das características próprias do sistema autonômico espanhol que o afastam de um modelo estatal federal, podem ser citadas: ausência de descrição constitucional de uma forma de Estado pré-definida e existência de um princípio de disponibilidade, mediante o qual Comunidades Autônomas assumem as competências que serão por elas tutelas em seus respectivos Estatutos de Autonomia ${ }^{4}$; a ausência de um Poder Constituinte Derivado Decorrente, uma vez que os Estatutos de Autonomia se revestem formalmente como Leis Orgânicas e devem ser submetidos a aprovação do Poder Central, o que afeta o elemento de auto-organização das unidades constitutivas; a não existência de um órgão de representação das Comunidades Autônomas perante a formação da vontade geral, pois o Senado Espanhol, em razão de sua composição,

\footnotetext{
${ }^{4}$ Ao assentar suas bases históricas no contexto de uma série de diversidades socioculturais representadas por distintas identidades regionais e nacionais presentes no território espanhol, que passaram a atuar na composição organizacional do poder diante da necessidade de proteção de seus interesses territoriais no âmbito jurídico-constitucional, a peculiar estrutura do pacto autonômico deriva de um princípio dispositivo, que estabelece uma proposta de abertura e flexibilidade para autodeterminação das unidades constitutivas, por meio de distintos processos de acesso à autonomia com a finalidade de conciliar diversidade e unidade, como destaca Isidre Molas: "De la pluralidad nacional y regional de la Nación española y del principio dispositivo que permite el acceso voluntario a la condición de Comunidad Autónoma y la asunción también voluntaria de las competencias, se deriva una organización política basada en la diferencia, que es el supuesto de hecho del Estado español constituído" (MOLAS, Isidre. Derecho Constitucional, p. 179. Madrid: Editorial Tecnos, 2010).
} 
representa mais propriamente as Províncias; presença, no âmbito constitucional dos chamados hechos diferenciales ${ }^{5}$.

Portanto, entre as particularidades presentes no sistema autonómicos encontra-se os denominados hechos diferenciales, que, nas palavras de Eliseo Aja, são compreendidos "como el reconocimiento constitucional y estatutario de los elementos de una personalidad histórico-política diferenciada en algunas CCAA, proporciona un fundamento objetivo para que las instituciones de las respectivas CCAA mantengan y desarrollen su propia personalidad más allá de la genérica potestad de autogobierno que comparten con las demás",6.

Constata-se que os hechos diferenciales se encontram dispostos em diversas passagens da Constituição Espanhola, tais como a constante do artigo $2^{\circ}$ que estabelece a diferença entre nacionalidades e regiões presentes no território espanhol; as relativas às distintas vias de acesso a autonomia determinadas pelos artigos 143 e 151 da CE; e possibilidade de assunção de níveis de competências diferidas pelas Comunidades Autônomas, conforme o artigo 148.2, CE, com fundamento no princípio dispositivo. Estes traços peculiares do Estado Autonômico se sedimentam, ainda, com maior robustez, nas previsões referentes ao direito civil e foral (art. 149.1.8, CE); no respeito aos direitos históricos dos territórios forais (Disposição Adicional $1^{\mathrm{a}}$ ); nas disposições organizacionais territoriais insulares, com a existência de Cabildos e Consejos (art. 141.4, CE); bem como no direito a manter língua (art. $3^{\circ}, \mathrm{CE}$ ), bandeiras e símbolos próprios (art. $4^{\circ}, \mathrm{CE}$ ) que estejam presentes na representação das características socioculturais de cada Comunidade Autônoma?

Sintetizando o conteúdo das ideias até então expostas, pode-se inferir que, ao representar expressão jurídico-constitucional das diversidades nacionais e

\footnotetext{
${ }^{5}$ Para verificação do tema: CONTIPELLI, Ernani. Federación y Estado Autonómico: Estudio de Derecho Constitucional Comparado Brasil - España. Granada: Editorial Comares, 2012.

${ }^{6}$ AJA, Eliseo. El Estado Autonómico: Federalismo y Hechos Diferenciales, p. 161. Madrid: Alianza Editorial, 2001.

${ }^{7}$ Novamente, utilizam-se os ensinamentos de Eliseo Aja para verificar os principais elementos de configuração dos hechos diferenciales recolhidos por certas Comunidades Autônomas, a saber: "Pais Vasco: Territorios Históricos, lengua, derecho civil foral, policía propia y sistema de concierto fiscal. Cataluña: lengua, derecho civil especial y policía propia. Galicia: lengua y derecho civil foral. Navarra: convenio fiscal, derecho civil foral, policía propia, euskera en zona vascoparlante. Canarias: cabildos y régimen económico fiscal especial. Islas Baleares: lengua, Consejos Insulares, derechos civil especial. Comunidad Valenciana: lengua y derecho civil. Aragón: derecho civil" (El Estado Autonómico: Federalismo y Hechos Diferenciales, p. 161. Madrid: Alianza Editorial, 2001).
} 
regionais historicamente reivindicadas na composição do território espanhol, os hechos diferenciales revelam o reconhecimento jurídico-constitucional das assimetrias que fazem parte integrante da própria organização e consolidação estrutural do pacto autonômico, para possibilitar a formação de um projeto comum de nação.

Entre os movimentos que expressam o plurinacionalismo do sistema autonômico espanhol, destaca-se o presente na Comunidade Autônoma de Catalunha, o qual, no contexto político atual, tem suscitado uma serie de controvérsias no sentido de obtenção de maiores competências, para adoção de uma proposta diferenciada de autogoverno, que atenda efetivamente ao conteúdo de suas particularidades territoriais, ou mesmo fazer valer um direito de secessão, por meio de uma consulta popular, via referendo, aos seus cidadãos, para criação de um novo Estado.

\subsection{Nacionalismo Catalão.}

Há que se destacar que, assim como todos os nacionalismos, o movimento nacionalista Catalão representa esforço histórico no sentido de preservar suas identidades culturais próprias, que denotam o seu sentimento de existir como um povo, que exerce sua autodeterminação com soberania. No transcorrer da história, pode se constatar que o nacionalismo catalão sempre esteve às voltas com inúmeras tentativas de absorção de suas raízes culturais peculiares, sobretudo, no que se refere à supressão do uso de sua língua.

Em breve abordagem histórica, o Principado de Catalunha origina-se no século XI com a união, promovida por Ramón Berenguer I (1035-1076), de uma serie de condados independentes, convertendo a região em um importante centro político e comercial na zona mediterrânea, tanto que, em 1137, já fazia parte da Coroa de Aragão, exercendo poder dominante. Após as epidemias da peste que atingiram a população catalã no século XIV, Catalunha passa a receber a influencia do Reino de Castilla sobre seus internos, situação que se consolidou com o casamento de Isabel, herdeira do reino de Castilla, e Fernando, herdeiro do reino de Aragão, o que determinou as origens das bases do atual Estado espanhol ${ }^{8}$.

\footnotetext{
${ }^{8}$ DIEZ MENDRANO, Juan. Naciones Divididas: Clase, Política y Nacionalismo en el País Vasco y Cataluña, p. 24/25. Madrid: Centro de Investigaciones Sociologicas, 1999.
} 
Interessante apontar que mesmo com a unificação foi permitida a preservação de diversos privilégios concedidos ás oligarquias locais, haja vista que os próprios reinos de Castilla e Aragão se consideravam como entidades políticas autônomas. Nesse panorama, os catalães, vinculados ao reino de Aragão, eram considerados como estrangeiros perante o reino de Castilla, sendo impedidos de participar de uma série benefícios para estímulo de seu comércio, como por exemplo, das riquezas geradas pela conquista da América e administradas exclusivamente por Castilla. Esse afastamento, por outro lado, motivou não apenas o fortalecimento de uma identidade cultural catalã, mas também o desenvolvimento de uma maior tendência à autonomia governamental em relação ao Poder Central do Reino de Castilla-Aragão, com o srugimento da Diputación del General ou Generalitat, que, em período posterior, após as guerras de sucessões, que conduziram Felipe V ao trono de Espanha, restou expedido o "Decreto de Nueva Planta", mediante o qual eram suprimidas as instituições políticas catalanas com a imposição das leis de Castilla e o uso oficial da língua castelhana.

Já no século XX, a identidade política e cultural catalã continua sofrendo atentados com as políticas unitaristas públicas realizadas pelo Poder Central espanhol, sobretudo, com as ditaduras de Primo Rivera (1923-1930) e de Francisco Franco (19391975), nas quais os impulsos nacionalistas da região foram contidos através da supressão das entidades representativas do autogoverno da região e a proibição do uso da língua catalã. Somente com o advento da Constituição de 1978 e transição para o regime democrático que se resgatam institucionalmente as particularidades autonômicas catalãs, com a aprovação de seu Estatuto de Autonomia (1979) e celebração das primeiras eleições para a composição de seu Parlamento (1980).

No momento político contemporâneo, o nacionalismo catalão se robustece com a busca de maior autogoverno por meio de processo de reforma de seu Estatuto de Autonomia, a tentativa de criação de um pacto fiscal para maior autonomia financeira da região, manifestações populares regidas pelo lema "Catalunya nou Estat d'Europa", e finalmente, com a "Declaración de Soberanía y el Derecho a Decidir del Pueblo de Cataluña" elaborada pela atual legislatura parlamentaria, que retrata o crescimento da vontade do povo catalão em fazer valer plenamente sua identidade cultural, com o inicio do processo para exercício do direito de decidir, via referendum, a sua continuidade como parte do Estado espanhol. 
Como arremate, saliente-se a existência da Disposição Adicional $1^{\mathrm{a}}$ no Texto Constitucional espanhol, que "ampara los derechos históricos de los territorios forales", marcando substancialmente, em termos financeiros, a sua concepção plurinacional, ao criar um sistema fiscal diferenciado para País Vasco e Navarra, no qual tais Comunidades Autônomas recebem os tributos de seus contribuintes e participam dos gastos gerais do Poder Central com a entrega de um valor determinado em acordo econômico: "ambas comunidades recaudan, como tributos concertados, la generalidad de los impuestos que integran el sistema impositivo estatal y transfieren una parte de las sumas recaudadas - el cupo - al Estado como contribuición a todos los servicios del Estado que no asuma la comunidad autônoma (defensa, representación exterior, p. ej.)"9.

Ocorre que tal disposição acaba por trazer instabilidade ao regular desenvolvimento do pacto associativo autonômico, em vista da não contemplação de benefícios similares para os demais nacionalismos existentes, como o de Catalunha, criando uma diferença substancial no sistema financeiro que, em grande parte, gera motivação para seu questionamento como um todo e, consequentemente, da própria unidade territorial. A impropriedade de se conceder tal direito ao País Vasco e Navarra, sem abranger as outras regiões que apresentam nacionalismos próprios, gera, atualmente, um alto grau de desconforto na manutenção do pacto associativo autonômico espanhol, que se vê diante de uma série de criticas e correndo grande risco de ruptura, sobretudo, com as movimentações atuais políticas direcionadas ao processo de independência de Catalunha.

Estas considerações demonstram os cuidados que devem ser tomados pelos Poderes Constituídos no reconhecimento jurídico de heterogeneidades regionais, haja vista que o estabelecimento de diferenças e a não atualização do sistema para distribuição equânime de benefícios entre unidades constitutivas que se encontram em uma mesma condição (minoria nacional), sem a adoção de um critério lógico e razoável de discriminação que pondere todos os interesses envolvidos, surte efeitos na integralidade da estrutura territorial, causando enfraquecimento dos vínculos de interdependência. Em tais casos, é imprescindível a busca das reais exigências dos interessados, com sua participação no processo de formação das decisões a eles

\footnotetext{
${ }^{9}$ FERREIRO LAPTZA, José Juan. Instituciones de Derecho Financiero, p. 62. Madrid: Marcial Pons, 2010.
} 
concernentes, para atualizar o sistema jurídico no sentido de encontrar um ponto de equacionamento para acomodação da situação e propiciar a legitimação democrática, confiabilidade e eficácia social das manifestações de poder político.

\section{Desobediência Institucional.}

Apresentadas as linhas gerais que envolvem o funcionamento da Teoria da Legitimação Democrática do Direito, bem como os aspectos relativos ao sistema autonômico espanhol e ao nacionalismo catalão, que servirão de substrato empírico para sua aplicação, nesse momento, pretende-se investigar a figura da desobediência institucional, a qual autoriza as unidades constitutivas, a negar-se temporariamente mediante protesto a cumprir determinações relativas ao pacto associativo territorial, justamente, para assegurar sua existência e garantir a integridade da base axiológica constitucional que o permeia, assim como o sentimento publico de justiça que a legitima.

Vale dizer que na hipótese em que o Poder Central ou mesmo uma determinada unidade constitutiva age persistentemente na degradação das bases informadoras dos laços associativos territoriais, após a utilização dos instrumentos previstos no ordenamento jurídico para solução do problema, as demais unidades constitutivas, devidamente justificadas na legitimação democrática da base axiológica constitucional, podem manifestar-se de forma contrária as decisões políticas estipuladas em âmbito nacional e pelos Poderes Constituídos, para preservar algo maior, o projeto constitucional de bem comum.

Afinal de contas, compreende-se que uma teoria firmada na presença de um conjunto de valores constitucionais dirigentes do Direito Positivo, que se legitima em um constante processo de interpretação que se atualiza na dinâmica das relações sociais, para se discutir a possibilidade de manifestação adequada da "desobediência" e de suas variações, deve fundar-se na ideia de existência de uma sociedade política e juridicamente assentada sob um regime democrático legitimamente instaurado, mas na qual ocorrem violações ao sentimento justiça, o que se pode compreender como afronta ao rol básico de valores constitucionais, os quais, no caso, atuam na formação e desenvolvimento do pacto associativo territorial, que deu ensejo à configuração do sistema estatal descentralizado. 
Pode-se desdobrar esse raciocínio, ponderando que a consciência coletiva comum apresenta-se como união de vontades dotadas de racionalidade e reveladoras dos laços de interdependência recíproca, que se manifestam e influenciam as demais para possibilitar a realização de ações no campo político-social, auxiliando na modulação de valores e ideologias presentes em determinada uma sociedade. Essa consciência coletiva comum deve corresponder, então, ao que se entende por sentimento de justiça, buscando na realidade concreta sua legitimação democrática e confiabilidade institucional suficiente, para ser devidamente refletida no âmbito normativo constitucional com a finalidade de lhe atribuir eficácia social.

Quando o conteúdo axiológico/ideológico destas consciências coletivas comuns não é respeitado na produção de decisões políticas, seus efeitos também são sentidos no campo da experiência concreta, surgindo questionamentos quanto à correspondência entre a interpretação que é dada ao sentimento de justiça pelos Poderes encarregados de salvaguardá-los e sua dinâmica vivenciada na realidade empírica, para, em um movimento rotativo, atingir a legitimação democrática, a confiabilidade institucional e a eficácia social do sistema jurídico positivo, o que conduz a abertura de espaços para a realização de protestos através de mecanismos como a desobediência civil ou institucional.

Em correspondência com as afirmações anteriores, ao tratar do tema sobre a desobediência civil, Jonh Rawls retrata os parâmetros em que sua manifestação ocorre em conformidade com a ideia de legitimidade democrática e com o sentimento de justiça que se expressa em conjunto com os valores que gravitam ao redor do projeto constitucional de bem comum, revelando o real conteúdo das vontades sociais: "invocamos la concepción de la justicia, comúnmente compartida, que subyace en el orden político. Se supone que en un régimen democrático razonablemente justo hay una concepción pública de justicia, por referencia a la cual los ciudadanos regulan sus asuntos políticos e interpretan la constitución. La violación persistente y deliberada de los principios básicos de esta concepción en cualquier periodo prolongado, especialmente la infracción de las libertades iguales fundamentales, invita a la sumisión o a la resistencia. Al cometer desobediencia civil, una minoría obliga a la mayoría a considerar si desea que así interprete su actuación, o si, en vista del sentido común de la justicia, desea reconocer las legitimas pretensiones de la minoría"10.

\footnotetext{
${ }^{10}$ RAWLS, John. Teoría de la Justicia, p. 33. México: Fondo de Cultura Económica, 2010.
} 
Deveras, a desobediência civil ou a institucional se fundam nos valores informadores da base axiológica constitucional que devem ser interpretados em conformidade com o sentimento de justiça, que se pretende realizar no cotidiano do plano concreto, em sintonia com a real evolução e desenvolvimento das instituições e processos propostos para sua legitimação democrática, confiabilidade e eficácia social, para alcançar a verdadeira interpretação que deve ser conferida às disposições normativas e programas políticos após a participação dos agentes interessados, por meio do protesto.

Especificamente, em relação à desobediência institucional, esse comportamento político pode se exteriorizar de múltiplas formas, como no caso em que a unidade constitutiva ampliaria seus poderes, incorporando em sua esfera de autonomia determinadas competências que originariamente estariam, por exemplo, a cargo do Poder Central, ou, ainda com a tomada de poderes fiscais, protestando através da recusa de envio ao poder central de parcela dos recursos financeiros que são arrecadados em seu campo territorial de influência, um dos casos configuradores de seu desdobramento como resistência fiscal, sendo relevante consignar que tais atitudes não pretendem se perdurar no tempo ilimitadamente, pois têm suas legitimidades atreladas à duração dos motivos que justificaram suas invocações, o que demonstra seu caráter essencialmente temporário, para não corromper definitivamente o pacto associativo territorial, revertendo o conteúdo das intenções iniciais desses atos, que de corretivos passariam a ser nocivos às bases axiológicas que permeiam o projeto constitucional de bem comum.

Com a pretensão de se atribuir melhor visualização ao assunto, é possível aproximar as figuras da desobediência institucional e resistência fiscal aos fundamentos propostos para desobediência civil. De acordo com a teoria formulada sobre o tema, os atos de desobediência civil são voluntários, não violentos, abertos e públicos, direcionados ao descumprimento de normas com manifesta intenção de obter algum tipo de melhora na sociedade e de fazer valer um dever moral, substituindo a lei descumprida ou o programa político contestado, devendo ainda ser aceita a sanção que o sistema jurídico impõe a realização do ato ${ }^{11}$.

Ora, no âmbito das relações entre entidades estatais há que se observar com reservas a aplicação analógica de conceitos advindos de outros campos, como os relativos às interações havidas entre Estado e cidadão, de qualquer modo, na hipótese

\footnotetext{
${ }^{11}$ VILAJOSANA, Josep Maria. L'Obediència de les LLeis. Barcelona: Editorial UOC, 2008.
} 
em que se pretende colocar em discussão neste trabalho, é possível aproveitar grande parte dos fundamentos teóricos da desobediência civil, sobretudo, o conteúdo de suas finalidades, que, ao buscar sempre uma melhora para as partes que são afetadas pelo ato descumprido, evidencia a necessidade de uma alteração da legislação ou mesmo de um comportamento político incompatível com o sentimento público de justiça e a melhor solução para interpretação da base axiológica constitucional.

Compreende-se, então, que o descumprimento consiste na única forma de reestabelecimento do bom caminhar das relações entre os participantes do pacto associativo territorial, inclusive, com a aceitação pela unidade constitutiva desobediente, quando for o caso, de possíveis sanções pelo seu ato, como forma de legitimar e atribuir eficácia a soberania constitucional, a qual deve permanecer intacta no processo de exteriorização da desobediência institucional, tendo em vista a necessidade de absoluto respeito ao seu núcleo axiológico.

Assim, diante de uma persistência na atitude de degradar os laços associativos territoriais pode ser legitimamente invocada a desobediência institucional, que - frise-se - não se tratam de propostas de institucionalização do caos em um sistema estatal descentralizado, mas sim de tornar justa e racional a participação de todos os envolvidos na consolidação e desenvolvimento dos vínculos de interdependência, que atuam sobre as unidades constitutivas, para afastar comportamentos externos que se revelem excessivamente ofensivos aos seus respectivos campos de autonomia.

Traçando um paralelo com figuras já conhecidas, pode-se inclusive afirmar que a desobediência institucional se enquadraria em uma espécie de “intervenção federal às avessas”, pois, em tal hipótese, a esfera de autonomia da unidade constitutiva, que se encontra constitucionalmente delimitada, atingida por posturas ofensivas por parte do poder central ou mesmo das demais unidades constitutivas, ao invés de ser restringida, é transitoriamente alargada pelo descumprimento, em vista da necessidade de chamar atenção das instituições e poderes constituídos para o ajuste que precisa ser realizado no processo de funcionamento do sistema estatal descentralizado para atender aos verdadeiros interesses comuns de todas as territorialidades e não apenas de algumas, fazendo valer o sentimento de justiça.

\section{Desobediência Institucional e Minorias Nacionais.}


Em sistemas políticos descentralizados plurinacionais, a convivência das minorias nacionais com os demais grupos demonstra sua persistência histórica em preservar os enlaces culturais, que as caracterizam, suportando a tendência de se incorporar ao conjunto hegemônico nacional que compõem o Estado, para movimentarse, especialmente, no sentido de obter maior autogoverno, seja com tentativa de ganhar grau de autonomia adequado dentro do sistema estatal em que se inseri para fazer valer seus interesses peculiares, e, em muitos casos, com a busca de sua condição como nação independente.

Justamente, nesse ponto, verifica-se que em relação às minorias nacionais, a especificidade que envolve o trato de seus interesses, exige na estruturação de poderes decorrentes do registro jurídico dessas assimetrias, a atribuição de uma autonomia diferenciada às unidades constitutivas que as representam com a concessão de maior liberdade política para tais territorialidades, o que, imprescindivelmente, reflete sua atividade de equacionamento axiológico das disposições constitucionais.

Há que salientar que entre as possíveis tratativas atribuídas aos movimentos nacionalistas no seio de um Estado pode constatar-se a opção por ações políticas centralistas de incorporação, com a finalidade de estreitar os vínculos culturais com as minorias e absorve-las na amplitude do nacionalismo hegemônico, o que deve ser realizado com certos cuidados e, sobretudo, com respeito às condições de legitimação democrática, tendo em vista a possibilidade de violação aos direitos civis e políticos dos cidadãos, bem como de autodeterminação dessas comunidades, ou mesmo, a formação de um ambiente hostil, marcado pela criação de grupos revolucionários propagandistas da secessão.

Entre algumas das praticas utilizadas para efetivar essas propostas de construção nacional/centralista podem ser citadas: política de colonização e de migrações internas, na qual o governo central estimula a população de diferentes regiões do país, pertencente ao grupo nacional hegemônico, a se transferir para o território onde se concentram as minorias; estipulação de fronteiras e delimitação das competências para unidades constitutivas em que se situam as minorias com vistas à fragmentação de seu poder político e seu âmbito de influência sobre os cidadãos; política de idiomas oficiais, como forma de reduzir o uso da língua própria do grupo minoritário e atraí-lo ao nacionalismo majoritário.

A outra opção, como já dito, é o caminho da garantia das especificidades culturais das minorias nacionais, conferindo-lhes, com base no Texto Constitucional e 
participação nas decisões relativas aos seus interesses, um rol de poderes e benefícios correspondente à especial autonomia que demandam a presença de tais grupos no seio de um único Estado, o que deve ser compreendido como atitude política de reconhecimento ajustada às próprias exigências históricas que propiciaram a formação e regular desenvolvimento do pacto associativo territorial entre povos com diferentes identidades culturais, além do respeito aos direitos fundamentais dos cidadãos pertencentes a esses grupos, que encontram no sentimento de pertença a esses grupos sua respectiva mobilidade social.

Nesse momento da investigação, em que se coloca a questão sobre a adoção de políticas para acomodação de nacionalismo, interessa tratar da possibilidade de ilustração da desobediência institucional em relação às assimetrias marcadas por minorias nacionais, tomando como o exemplo do caso de Catalunha. Voltando atenções para as considerações anteriores, restou compreendido que a política de idiomas pode ser aplicada como um dos mecanismos de centralização de interesses na construção das diretrizes nacionais, cumprindo um papel direcionado para tentativa de implantação de caracteres homogêneos a um sistema estatal descentralizado assimétrico.

$\mathrm{Na}$ hipótese de que a política educacional adotada por um Estado Plurinacional, com a finalidade de patrocinar a purificação idiomática, venha desconsiderar e afrontar a esfera de autonomia de uma minoria nacional caracterizada por esse aspecto, após o pronunciamento de uma das esferas de poder positivadas pelo sistema constitucional, revela-se perfeitamente legitimo que a unidade constitutiva atingida por tal ato político recuse-se a cumprir suas diretrizes justificada na ofensa a sua identidade cultural. Tal fato se enquadra nas discussões em torno do modelo linguístico adotado pelas escolas catalãs, o qual, por força da política educacional adotada pelo Poder Central, seguida por orientação jurisprudencial do Tribunal Constitucional, acaba por sofrer uma inversão de valores priorizando o castelhano ao catalão como idioma em que devem ser ministradas as aulas, o que levou a Generalitat de Catalunha a descumprir tais diretrizes normativas, com base na violação de sua autonomia diferenciada reconhecida constitucionalmente, que protege a pluralidade linguística no sistema educacional a ser adotado pela região.

Outro exemplo plausível de desobediência institucional pode ser manifestado no que diz respeito à utilização dos símbolos nacionais (hino, bandeira, brasão,...), os quais, em virtude de sua representatividade ideológica, possuem grande clamor político-social nos sistemas estatais descentralizados plurinacionais. Caso sejam 
adotadas medidas pelo governo central que vedem ou criem impedimentos à utilização de símbolos próprios das minorias nacionais que representem seu sentimento de identidade, certamente, se está diante de mais uma possibilidade de aplicação da desobediência institucional, haja vista a violação aos seus traços étnico-culturais que caracterizam historicamente tais grupos e que se encontram expressos em seus símbolos. Recentemente, em Catalunha, diversos municípios pertencentes à Província de Lérida são objeto de procedimento administrativo sancionador promovido pelo Poder Central, pelo fato de não içarem a bandeira espanhola em seus edifícios públicos. Ocorre que a atitude que levou as autoridades destas localidades a descumprirem a lei, promovendo o protesto por desobediência institucional, encontra-se fundamentada, justamente, na ausência de identificação cultural da população com os símbolos espanhóis e o sentimento de pertença à nação catalã.

Esse descumprimento também pode se expressar em termos financeiros, com a resistência fiscal, quando os mecanismos de transferências intergovernamentais fundados na solidariedade interterritorial estabelecem patentes diferenças em relação à minoria nacional ou prejudiquem seu desenvolvimento com a ausência de comprometimento por parte da maioria nacional para com o projeto constitucional de bem comum. Como caso emblemático pode ser citada a resistência fiscal proposta pelos Municípios de Lleida e Gallifa, ambos em Catalunha, que como forma de protesto nacionalista para criação de um território livre e soberano em tal região, tais localidades manifestaram-se no sentido de transferir o Imposto de Renda Pessoa Física recolhido em seus territórios diretamente para agência tributária catalã e não para os cofres do poder central. $\mathrm{O}$ protesto em tal situação se expressa na etapa procedimental das transferências, pois os Municípios descumprem a forma estabelecida, baseados na luta pela concessão de maior autogoverno para região, e realizam seus pagamentos diretamente para o órgão administrativo fiscal regional, ainda que esse em momento posterior repasse tais valores ao governo central.

Os exemplos anteriormente retratados demonstram que a legitimação democrática das disposições normativas relativas à determinação da esfera constitucional de autonomia diferenciada conferida à Comunidade Autônoma de Catalunha não se sustentam diante das transformações sofridas no sua identidade como minoria nacional, o que, certamente, conduz a uma serie de atos de desobediência institucional para fazer valer o sentimento concreto da população, devendo os Poderes Constituídos adotar uma política de acomodação que leve em consideração essa 
realidade, manifestando, inclusive, sua concordância para com a realização do exercício do direito de consulta para decidir a continuidade ou não da região como parte do Estado espanhol.

\section{Conclusão}

Quando uma determinada política adotada pelo governo central venha afrontar o traço peculiar que caracteriza uma minoria nacional, rompendo com o conteúdo histórico do pacto associativo territorial que caracteriza a formação do sistema estatal descentralizado, está assegurado, o protesto pela desobediência institucional, a recusa ao cumprimento de determinações ofensivas a sua especial autonomia pautada na legitimação democrática do ordenamento jurídico, que deve levar em consideração sentimento publico de justiça associado à interpretação dos valores que formam a base do Texto Constitucional.

Tal proteção motiva-se, especialmente, no fato de que uma minoria nacional, inserida em um sistema estatal dominado por interesses de um grupo nacional hegemônico, deve dotar-se dos instrumentos necessários para seguir existindo como nação, para não ver suprimido seu direito de autodeterminação e desaparecer, mas, sim, preservar sua identidade cultural, ainda quando falhem os elementos institucionalizados para proteção de sua especial situação, acarretando na possibilidade de utilização da desobediência institucional.

Assim, na estruturação e desenvolvimento dos sistemas estatais descentralizados se constata a necessidade de criação de procedimentos com fundamento constitucional que possibilitem um constante canal de intermediação entre distintos níveis de governo, a fïm de conciliar interesses territoriais e participação política dos cidadãos e desvendar o real conteúdo de suas especificidades, buscando a melhor solução que afaste, por meio do consenso dos agentes concernidos, um possível déficit de legitimidade do poder que venha degradar os laços de interdependência que assegurem a manutenção do pacto associativo nacional.

Especificamente, no caso de Catalunha e suas relações com o Poder Central Espanhol constata-se a perda de legitimidade democrática, sendo os casos de desobediência institucional correntes no território daquela região um termômetro que comprova essa situação, o que demanda a utilização de procedimentos de interpretação das disposições normativas constitucionais em correspondência com sua base axiológica 
ditada pelo sentimento publico de justiça dos interessados nas decisões políticas referidas a delimitação da autonomia diferenciado exigida por essa minoria nacional, o povo de Catalunha e, se para tanto for necessário, que se instaure o procedimento de consulta para que eles mesmos decidam democraticamente os seus próprios caminhos, seja com maior parcela de autogoverno, seja como nação independente.

\section{Bibliografia}

AJA, Eliseo. El Estado Autonómico: Federalismo y Hechos Diferenciales. Madrid: Alianza Editorial, 2001.

CONTIPELLI, Ernani. Federación y Estado Autonómico: Estudio de Derecho Constitucional Comparado Brasil - España. Granada: Editorial Comares, 2012.

DIEZ MENDRANO, Juan. Naciones Divididas: Clase, Política y Nacionalismo en el País Vasco y Cataluña. Madrid: Centro de Investigaciones Sociologicas, 1999.

FERREIRO LAPTZA, José Juan. Instituciones de Derecho Financiero. Madrid: Marcial Pons, 2010.

HÄBERLE, Peter. Hermenêutica Constitucional - A Sociedade Aberta dos Intérpretes da Constituição: Contribuição para Interpretação Pluralista e "Procedimental" da Constituição. Porto Alegre: Sérgio Antonio Fabris, 2002

LOCKE, John. Segundo Tratado sobre el Gobierno Civil. Madrid: Alianza Editorial, 2012.

MOLAS, Isidre. Derecho Constitucional. Madrid: Editorial Tecnos, 2010

RAWLS, John. Teoría de la Justicia. México: Fondo de Cultura Económica, 2010.

VILAJOSANA, Josep Maria. L'Obediència de les LLeis. Barcelona: Editorial UOC, 2008. 